\title{
Gestão Ambiental Integrada de Bacias Hidrográficas: Bacia do Rio Cachoeiras - São Mateus do Sul - PR
}

\author{
Harry Alberto Bollmann \\ Instituto de Saneamento Ambiental da PUCPR - Instituto de Pesquisas Hidráulicas da UFRGS \\ bollmann@rla01.pucpr.br
}

David da Motta Marques

Instituto de Pesquisas Hidráulicas da UFRGS

mottamarques@cpovo.net

Recebido: 05/11/99 - revisão: 12/12/00 - aceito: 22/06/01

\begin{abstract}
RESUMO
A gestão ambiental integrada de bacias hidrográficas pode ser feita usando a abordagem multicriterial da Programação por Compromissos, envolvendo a identificação de um ponto de equilibrio ambiental e sócio-econômico representativo para a bacia, bem como de sua distância a um ponto hipotético considerado como referencial. Como resultado da aplicação desta metodologia à Bacia Hidrográfica do Rio Cachoeiras/PR, além da caracterização ambiental e sócio-econômica da bacia, elaborou-se uma estratégia de priorização de investimentos para se atingir um hipotético cenário onde a situação ambiental da área e as condições sócio-econômicas da população têm igual importância. A aplicação desta aproximação mostra o seu potencial como instrumento de gestão.
\end{abstract}

Palavras-chave: gestão; integrada; bacia.

\section{INTRODUÇÃO}

As práticas existentes de mensuração da influência das atividades antrópicas no meio são controversas e raramente conseguem realizar ligações diretas entre a sócio-economia e os fatores ambientais. Pela sua conotação setorial, a variedade de indicadores e das técnicas de medição em uso têm, na verdade, tornado esta valoração comparativa ainda mais difícil. Para o Instituto Internacional para o Desenvolvimento Sustentável do Canadá (IISD, 1998), a abordagem setorial, de fato, compõe-se em uma barreira para o desenvolvimento de indicadores sistêmicos e de índices de agregação, em ordem superior, destes indicadores.

Entretanto, a ação de medir, como um instrumento indispensável para operacionalizar a implementação de políticas norteadoras do desenvolvimento humano, auxilia tanto aos decisores quanto ao cidadão comum na tarefa de conceitualizar objetivos, estudar alternativas, fazer escolhas e ajustar dinamicamente as políticas e objetivos, baseando-se na avaliação do seu estado atual. Mesmo que se possa contestar os valores absolutos obtidos como resultado da aplicação deste ou daquele índi- ce ou indicador, não se pode negar os benefícios obtidos da análise e interpretação destes mesmos resultados, quando se conhecem as limitações intrínsecas à medição efetuada, e quando se obtém séries consistentes de dados que possam fornecer informações secundárias para subsidiar uma análise estatística das tendências gerais das grandezas que foram objeto de investigação.

Tanto no que tange aos aspectos sociais, econômicos ou culturas, como no caso ambiental, existe uma infinidade de indicadores utilizados para os mais diversos fins. Resta ao gestor a escolha criteriosa daqueles que melhor representem as peculiaridades da área objeto de suas considerações. Somente a aplicação contínua de métodos de indicação da qualidade ambiental permitirá uma análise científica da evolução dos padrões de uso e ocupação do solo e suas relações com a qualidade ambiental. A divulgação dos resultados destas análises permitirá que a comunidade possa avaliar e acelerar seu processo de busca do seu próprio ponto de equilíbrio entre o desenvolvimento sócioeconômico e a conservação ambiental.

Os instrumentos para a promoção do Gerenciamento Ambiental podem ser classificados, de 
forma não excludente, em jurídicos (comando e controle), econômicos e multicriteriais. Pelos instrumentos jurídicos seriam estabelecidos limites à atuação dos agentes, cuja obediência seria estimulada por penalização dos infratores, ou através de critérios de compensação, conjugados ao monitoramento e polícia ambiental. A outorga do uso da água ou de instalação de atividades que potencial ou efetivamente a poluam, seriam alguns dos instrumentos adotados. Nos casos em que ocorre degradação ambiental por efeito da ação dos agentes, seria também realizada uma Avaliação de Impacto Ambiental visando a sua consideração, bem como a recomendação de medidas mitigadoras e de planos de monitoramento.

As soluções econômicas procuram estabelecer, através de instrumentos de mercado, da imposição de preços, taxas, subsídios e rateios (além de outros instrumentos econômicos), o mesmo equilíbrio buscado pela aplicação dos instrumentos legais.

Já a abordagem multicriterial pode desenvolver uma estratégia de otimização da gestão dos recursos naturais baseando a intensidade e a diversidade de ações na ponderação de critérios múltiplos determinados a priori. Este tipo de abordagem baseia-se na possibilidade de identificação dos principais subsistemas intervenientes no processo que se quer otimizar, e para cada um deles, na determinação de funções objetivas claras e de equações de restrição que modelem adequadamente o comportamento de cada subsistema, baseado-se em um número finito de variáveis indicadoras.

No caso do ambiente urbano, o entendimento das alterações provocadas tem sido historicamente abordado do ponto de vista reducionista, estudando os fenômenos isoladamente, ou quando muito, agrupados por campo do conhecimento (Duval, 1993; Funtowicz e Ravetz, 1994). A consideração conjunta destes fenômenos é bem mais recente, de modo que a escolha das metodologias de abordagem, a identificação dos principais elementos influentes e a elaboração do modelo mais apropriado fazem parte integrante da construção do conhecimento.

Uma das aproximações válidas neste sentido é proposta em UNESCO (1987) que procura, através da abordagem sistêmica, aplicar o Método de Programação por Compromissos de modo a obter uma noção geométrica de qualidade baseada na distância entre o ponto de equilíbrio ecológico e econômico inferido, e um ponto ideal considerado como referência. Quanto menor for esta distância, mais próximo ao ideal se apresenta o objeto de estudo.

Este trabalho pretende aplicar a Metodologia de Programação por Compromissos como uma base estrutural para a avaliação integrada de bacias hidrográficas. Na análise, serão avaliadas as dimensões ambiental e antrópica de uma pequena bacia hidrográfica no Município de São Mateus do Sul (Paraná) segundo dados e informações existentes.

\section{METODOLOGIA}

Na atualidade, muita ênfase tem-se dado à tentativa de compreensão dos fenômenos naturais sob o ponto de vista sistêmico. Com razão, a gestão dos recursos naturais (cada vez mais escassos ou comprometidos), necessita de um entendimento mais complexo, via de regra carregado de variáveis que garantam a participação de elementos anteriormente considerados como secundários ou menos influentes.

Para a gestão ambiental de bacias hidrográficas, dentro da coleção de vários modelos atualmente existentes, selecionou-se para estudo e aplicação, uma proposição apresentada em UNESCO (1987). Este sistema de gestão ecológico/econômico é uma estratégia de gestão ambiental em bacias hidrográficas baseada em um balanço ponderado de índices obtidos em ações de monitoramento da região influente de modo a observar alterações decorrentes da construção de obras de engenharia ou utilização de recursos naturais (renováveis ou não). Neste caso, considera-se como área influente a região compreendida por sua bacia hidrográfica.

Desta forma, devem ser selecionados indicadores de desenvolvimento para a região considerada, bem como indicadores de qualidade ambiental, os quais comporão a base fundamental de dados a serem monitorados. Algumas premissas devem ser a princípio verificadas. Entre elas, as mais importantes podem ser elencadas como segue:

- que não se limite a metodologia aos fatores hidro-ecológicos, mas que a ação pretendida seja avaliada como uma parte de um sistema ambiental que considere aspectos físicos, químicos, biológicos, econômicos, sociais, e culturais; 
- que se possa elencar indicadores de desenvolvimento para cada componente;

- que se possa desenvolver e aprimorar ferramentas de monitoramento com estudos a curto, médio e longo prazos de modo a conferir a acuidade necessária aos indicadores selecionados;

- que a metodologia seja prática para os propósitos de gestão, não necessitando de sofisticações matemáticas e computacionais;

- que seja incluído, no escopo das decisões de gestão, os conceitos de desenvolvimento sustentável e da prudência no trato com as questões sociais e ambientais.

Uma vez estabelecidos os subsistemas interferentes bem como os indicadores adequados a cada subsistema, passa-se a executar atividades de monitoramento periódico a fim de levantar os dados necessários à obtenção dos índices, conforme Tabela 1.

Os termos Iamb1, Iamb2, Ieco, Icul, Isoc são indicadores quaisquer selecionados para avaliar os subsistemas ambiental, econômico, cultural e social, respectivamente. Para estes indicadores, na fase de medição indicada na Tabela 1 , são calculados os respectivos índices que devem ser comparados a padrões previamente estabelecidos.

A metodologia permite ao gestor o diagnóstico do estado do ambiente, como também determinar o comportamento do projeto proposto nas suas características ecológicas e econômicas. No caso de se procederem ações mitigadoras ou compensatórias dos impactos decorrentes da obra de engenharia ou uso dos recursos naturais existentes, igualmente pode-se incluir tais medidas no escopo do diagnóstico integrado do projeto, determinando a nova situação de equilíbrio. Ou ainda, poderão ser considerados vários cenários futuros de impacto de medidas corretivas na avaliação e na composição de um equilíbrio econômico e ecológico desejável para a situação. A aproximação ao ponto ideal de equilíbrio pode ser efetuada por dois métodos distintos:

- Método Prévio, no qual as alternativas são estudadas na etapa de planejamento;

- Método Corretivo, baseado em atividades complementares (de mitigação ou de compensação dos impactos ambientais) e de incremento econômico do projeto.
Tabela 1. Estratégia de abordagem.

\begin{tabular}{llll}
\hline Subsistema & Indicador & Índices & Padrões \\
\hline Ambiental & Iamb1 & $\underline{\text { Iamb1 }>\text { Pamb }}$ & Pamb \\
& Iamb2 & Iamb2 & \\
Econômico & Ieco & Ieco $=5$ & Ieco $>0$ \\
Cultural & Icul & Icul $>0$ & Icul $=0$ \\
Social & Isoc & Isoc $=10$ & Isoc $=5$ \\
Identificação & Estruturação Medição & Comparação \\
\hline
\end{tabular}

Fonte: UNESCO (1987).

Uma das razões para a escolha desta metodologia, é a premissa de que se possa comparar o ponto de equilíbrio atual com um ponto ideal (E) inicialmente teorizado por Paretto (apud UNESCO, 1987) de uso pleno econômico sem nenhum impacto ambiental. Na prática, o Ponto E (Figura 1) é intangível, mas algumas combinações entre subsistemas de desenvolvimento e de proteção ambiental podem ser consideradas no sentido de alterar o equilíbrio existente, aproximando-o progressivamente deste ponto ideal.

O esquema apresentado na Figura 1 representa o campo das soluções possíveis de um indicador bi-dimensional que procura diagnosticar o estado dos sistemas sócio-econômico e ambiental em uma determinada região. Uma vez que as escalas estão normalizadas, seus valores numéricos variam de 0,0 (pior situação) a 1,0 (melhor situação) de modo que a situação atual pode ser referenciada nesta escala como um ponto intermediário entre os extremos. Observa-se que o ponto E de coordenadas $(1,0 ; 1,0)$ sintetiza o conceito de Desenvolvimento Sustentável, pois estabelece a satisfação máxima das demandas sócio-econômicas com nenhum impacto ambiental, garantindo sua perpetuação.

Os sistemas naturais (físico-químico e biológico) podem ser relativamente bem observados nos seus aspectos qualitativos e quantitativos. Da mesma forma, os indicadores econômicos envolvidos. Entretanto, algum cuidado deverá ser tomado na ponderação dos aspectos sociais e culturais.

Para tratar conjuntamente os índices obtidos por indicadores de natureza tão variada, utilizar-se-á o Método de Análise Multicriterial, que representa um grande avanço desde a Teoria de Critério Ótimo Entre Elementos Não Mensuráveis de Paretto. 


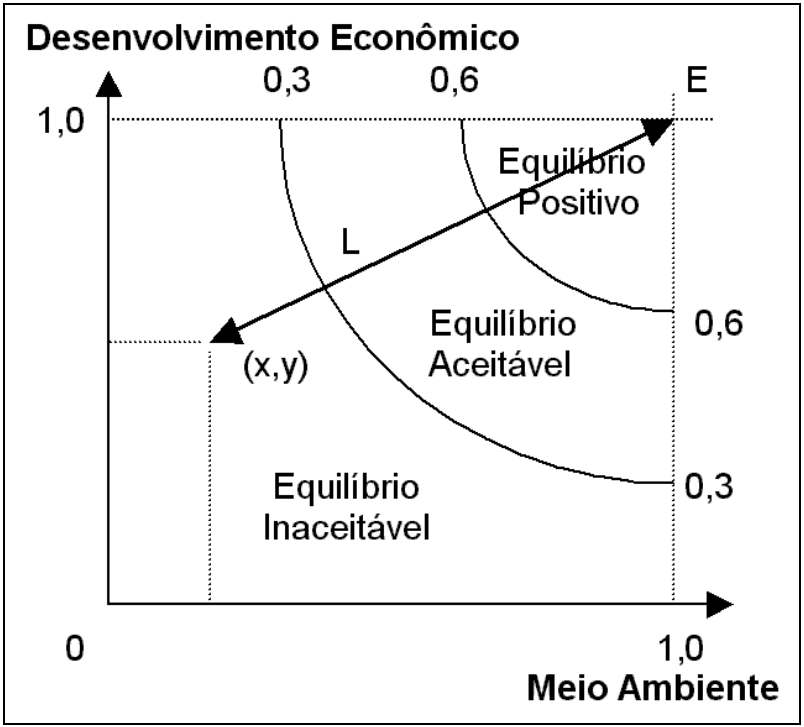

Figura 1. Base conceitual do modelo de avaliação do equilíbrio econômico e ecológico em relação ao Ponto Ideal (E). Fonte: UNESCO, (1987).

De uma maneira resumida, a metodologia de aplicação do sistema de gestão proposto segue os seguintes passos:

- definição do objeto do estudo e sua área de abrangência (escala local, bacia hidrográfica, etc.);

- seleção dos indicadores primários, que são medidas diretas das variáveis envolvidas (ex.: $\mathrm{pH}$, temperatura, número de habitantes etc.);

- seleção das unidades de medida dos indicadores (comparação com padrões);

- agrupamento dos indicadores primários em indicadores secundários formados pela agregação dos indicadores primários em estruturas integrativas (ex.: Indice de Qualidade das Águas, Potencial Econômico, etc.);

- agrupamento dos indicadores secundários de mesma natureza em indicadores terciários (ecologia, sócio-economia, etc.). UNESCO (1987) e Mutz (1991) recomendam a seleção de, no máximo, dois ou três indicadores terciários. A metodologia permite a seleção de mais do que três, mas o resultado final será mais complexo na sua execução e interpretação;

- consideração de "pesos" aos índices para a ponderação do resultado numérico;

- levantamento das informações básicas (monitoramento e coleta de informações);
- aplicação da metodologia descrita em UNESCO (1987), a qual atribuirá um valor numérico à situação atual;

- repetição temporal do monitoramento para observação da dinâmica de equilíbrio do projeto.

O ponto mais significativo desta estratégia de gestão baseia-se na sua flexibilidade de adaptação às mais variadas situações de aplicação, podendo-se considerar tantas variáveis quantas forem necessárias para que o modelo construído atinja os objetivos inicialmente fixados pelo gestor. Da mesma forma, é possível explorar elementos de difícil mensuração econômica. Na realidade certas variáveis (como por exemplo os componentes culturais) não podem ser facilmente mensurados em uma escala econômica. Entretanto, pode-se estruturar, com alguma facilidade, uma escala própria de valores sobre a qual plotar os resultados obtidos em campo.

Poucas metodologias até agora apresentadas possibilitam que cada componente possa ser valorado contra uma escala estabelecida para tal com parâmetros de mesma espécie. Assim, não é necessário transformar componentes ecológicos em financeiros (espécies diferentes), ou ainda componentes culturais em financeiros (idem), cujos resultados têm apresentado mais limitações do que indicações ao seu uso.

Outra questão de significativa importância é a consideração do Ponto E (Ponto de Equilíbrio), que espelha a base fundamental do Desenvolvimento Sustentável, uma vez que expressa, segundo Paretto (apud UNESCO, 1987), o ponto de máximo aproveitamento econômico do recurso com mínimo ou nenhum impacto ambiental diverso.

Observa-se novamente que este ponto consiste em um equilíbrio utópico, inatingível, mas que deve ser procurado com cada vez mais ímpeto de modo a atender, de uma forma que preserve, com condições mínimas de qualidade, a vida em todas as suas formas.

\section{CARACTERIZAÇÃO DA ÁREA DE ESTUDO}

O município de São Mateus do Sul (Latitu-

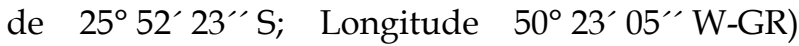
situa-se no Estado do Paraná, distante $150 \mathrm{~km}$ à oeste da capital, Curitiba. O município possui uma 
área de $1.334,522 \mathrm{~km}^{2}$ com uma altitude de $760 \mathrm{~m}$ acima do nível médio do mar.

O clima é Subtropical Úmido Mesotérmico, verões frescos (temperatura média inferior a $22^{\circ} \mathrm{C}$ ) e invernos com ocorrências de geadas severas e freqüentes (temperatura média inferior a $18^{\circ} \mathrm{C}$ ), não apresentando estação seca.

A população total é de 36.252 habitantes estimados para 01/07/1999, sendo 19.290 habitantes urbanos e 16.962 habitantes rurais. A taxa anual de crescimento da população urbana é de $+2,43 \%$, enquanto que a população rural apresenta uma taxa negativa de crescimento, estimada em $-0,19 \%$. As projeções foram feitas pelo Programa PARANACIDADE, tendo por base o Censo Demográfico de 1991 e a contagem populacional de 1996 do IBGE.

O extrativismo é economicamente marcante na sua história econômica, principalmente na exploração do xisto, lenha e erva-mate. A agricultura de subsistência baseada no conceito de faxinais, ainda desempenha um papel significativo, e foi o responsável pela preservação de grande parte dos remanescentes dos extratos florísticos naturais presentes na região.

Os aspectos econômicos e sociais mais relevantes são os seguintes:

- Participação no PIB Municipal:

Agropecuária $=17 \%$;

Indústria $=31 \%$;

Serviços $=52 \%$.

- Produto Interno Bruto:

US\$ 74.100.254,71;

PIB per capita $=$ US\$2.183,34/hab.

- População Economicamente Ativa: 20.126 habitantes.

- Economias Existentes:

Ligações de Água = 5.419;

Ligações de Esgoto = 147;

Ligações de Energia Elétrica = 8.602 .

- Educação na Área Urbana:

Ensino Público:

Fundamental $=6.182$ matrículas;

Médio $=1.030$ matrículas;

Terceiro Grau = não há.

Ensino Particular:
Fundamental $=509$ matrículas;

Médio $=66$ matrículas;

Terceiro Grau = não há.

\section{A bacia do rio Cachoeiras}

O rio Cachoeiras (Figura 2) é um dos afluentes perenes da margem direita do rio Iguaçú e se encontra localizado no município de São Mateus do Sul sendo que seu talvegue principal apresenta uma orientação norte-sul, atravessando uma área rural.

As principais características físicas (Tabela 2) foram determinadas conforme indicação metodológica constante em Villela e Mattos (1975) a partir da restituição de uma imagem digital da área em escala 1:8000, com curvas de nível de 5 em 5 metros. As medidas de área e os comprimentos especificados foram verificados com valores obtidos de forma computacional, em ambiente de CAD, da restituição digital de fotografias aéreas.

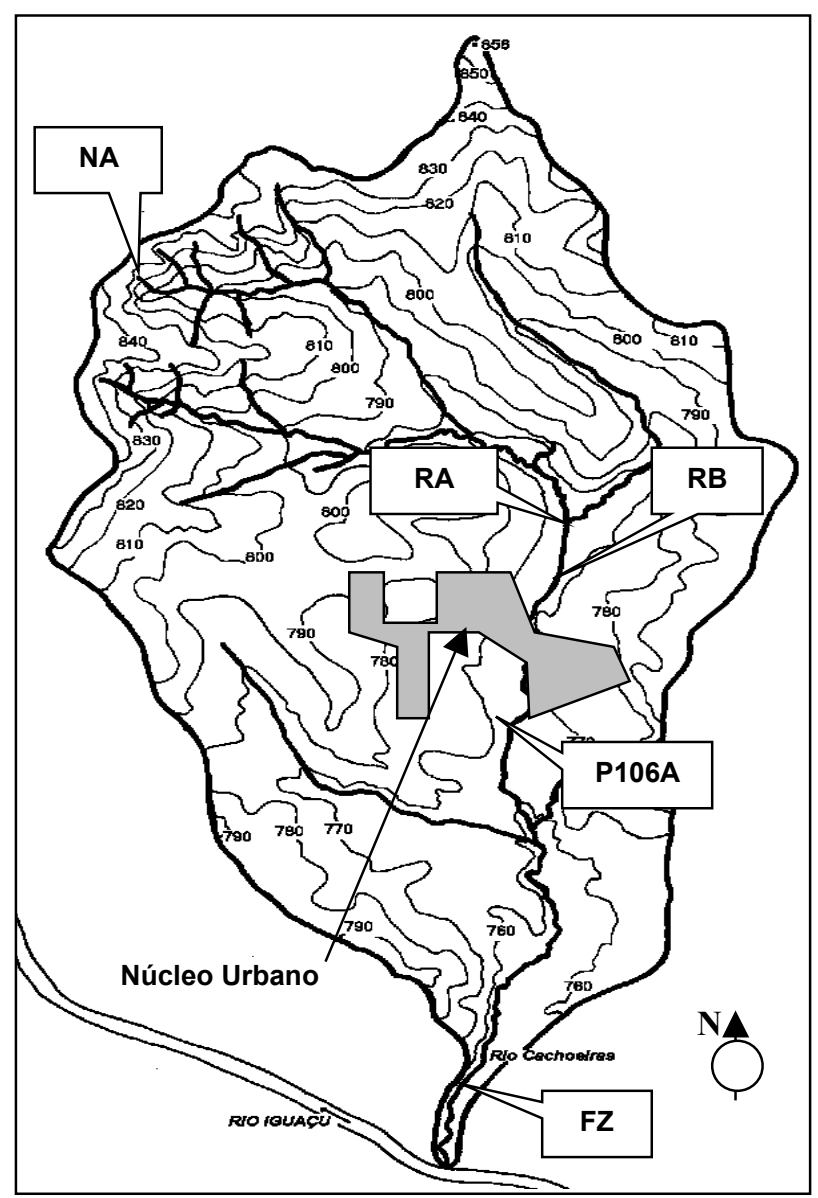

Figura 2. Bacia hidrográfica do rio Cachoeiras - São Mateus do Sul/PR. 
Tabela 2. Características físicas da bacia hidrográfica do rio Cachoeiras.

\begin{tabular}{lc}
\hline Característica & Valor \\
\hline Área de drenagem & $8,019 \mathrm{~km}^{2}$ \\
Perímetro da bacia & $17,61 \mathrm{~km}$ \\
Coef. compacidade & 1,74 \\
Fator de forma & 0,16 \\
Declividade média da bacia & $0,055 \mathrm{~m} / \mathrm{m}$ \\
Declividade mediana da bacia & $0,080 \mathrm{~m} / \mathrm{m}$ \\
Altitude máxima da bacia & $856 \mathrm{~m}$ \\
Altitude mínima da bacia & $758 \mathrm{~m}$ \\
Altitude média da bacia & $790 \mathrm{~m}$ \\
Altitude mediana da bacia & $798 \mathrm{~m}$ \\
Densidade de drenagem & $2,53 \mathrm{~km} / \mathrm{km}{ }^{2}$ \\
Ext. escoamento superficial & $0,1 \mathrm{~km}$ \\
Ordem do curso d'água & Terceira \\
Sinuosidade & 1,02 \\
Declividade de Álveo S1 & $0,094 \mathrm{~m} / \mathrm{m}$ \\
Declividade de Álveo S2 & $0,036 \mathrm{~m} / \mathrm{m}$ \\
Declividade de Álveo S3 & $0,025 \mathrm{~m} / \mathrm{m}$ \\
\hline
\end{tabular}

Os valores obtidos para o coeficiente de compacidade e fator de forma reiteram a forma longilínea da bacia e sua baixa propensão à enchentes expressivas. Embora existam poucas informações sobre a densidade de drenagem das bacias brasileiras, pode-se afirmar que este índice varia de $0,5 \mathrm{~km} / \mathrm{km}^{2}$ para bacias com drenagem pobre, a $3,5 \mathrm{~km} / \mathrm{km}^{2}$ (ou mais) para bacias excepcionalmente bem drenadas (Villela e Mattos, 1975). Para o caso do rio Cachoeiras, a Densidade de Drenagem calculada denota uma boa drenagem da bacia, corroborando para o baixo valor encontrado para a Extensão do Escoamento Superficial. Pode-se também observar que a bacia possui uma declividade baixa e relativamente constante ao longo de grande parte de sua área, o que resulta numa redução dos picos de enchente devido à baixa velocidade de escoamento.

Outro fator que pode ser observado na análise das altitudes é a Altura Média da Seção de Controle, a qual representa uma carga potencial hipotética a que estão sujeitos os volumes de excesso de chuva e constitui um fator que afeta o tempo que levariam as águas para atingir a seção de controle. Essa altura, determinada pela diferença entre a elevação mediana e a elevação do leito na desembocadura do rio, é de $40 \mathrm{~m}$.

Em relação à Declividade de Álveo, a declividade entre a foz e a nascente está representada por $S_{1}$. Um valor mais racional e representativo da declividade de álveo é obtido pelo perfil longitudinal, uma linha $S_{2}$ tal que a área compreendida entre ela e a abscissa seja igual à compreendida entre a curva do perfil e a abscissa. Outro índice representativo do perfil longitudinal do curso d'água é o que recebe o nome de declividade equivalente constante (representado pela declividade $S_{3}$ ). Esse índice vem dar uma idéia sobre o tempo de percurso da água ao longo da extensão do perfil longitudinal.

Dada a inexistência de dados hidrológicos para a bacia, os parâmetros constantes da Tabela 2 servem apenas para fornecer indicações gerais sobre o seu comportamento hidrológico. Não necessariamente explicam o comportamento hidrológico em eventos raros ou de curta duração como as precipitações intensas, que em grande parte são responsáveis por transtornos aos sistemas natural e antrópico.

\section{RESULTADOS E DISCUSSÃO DA APLICAÇÃO DO MODELO}

\section{Variáveis sociais}

Apesar da fácil compreensão da abrangência e importância das variáveis ligadas ao bem estar social, a determinação de indicadores sociais não é tão simples (Ajzemberg, 1986). Os elementos dificultadores deste processo têm origens diversas, mas podem ser principalmente divididos em três categorias: dificuldades metodológicas, dificuldades administrativas e problemas de escala.

Em relação à primeira, ainda não se chegou a um consenso sobre quais os elementos necessários para garantir uma condição mínima de vida digna ao homem. Apesar de se reconhecer a necessidade social da saúde, nutrição, educação, e do saneamento básico, além do acesso à energia, transporte e à segurança pública (entre outros), a sociedade humana atual é muito complexa, e a satisfação do que se convencionou como "elementos do bem estar social" sofre variações temporais e espaciais baseadas na estrutura cultural e econômica de cada segmento populacional determinado. Assim, os elementos importantes para determinado grupo podem não ter a mesma ordem de importância ou prioridade para outro. Marcantes são as diferenças observadas, por exemplo, entre os padrões urbanos e rurais muitas vezes presentes em uma mesma bacia hidrográfica. 
$\mathrm{O}$ acesso à mídia e o padrão cultural local podem ditar regras ou mesmo agregar valores artificiais à bens de consumo secundários que se tornam algumas vezes mais importantes para o conjunto da sociedade do que os bens necessários à manutenção da vida. Neste contexto, dificilmente se pode determinar sem contra-argumentações quais os elementos sociais necessários e, deste modo, construir indicadores eficientes. Ainda que isto fosse possível, as administrações municipais, estaduais e federal têm divergido significativamente em relação aos padrões de cobertura e de qualidade dos serviços considerados essenciais.

Com relação às dificuldades administrativas, uma vez que os órgãos da administração pública nas várias esferas são hierarquizados e organizados por políticas setoriais individualizadas, as informações necessárias para se conhecer os aspectos multifacetados da qualidade social de uma determinada parcela da sociedade compõem bancos de dados parciais em diversas instituições municipais, estaduais, federais (ou mesmo particulares) cujas metodologias de levantamento e atualização muitas vezes não coincidem. Esta discrepância metodológica gera conflitos de informação tanto no ponto de vista qualitativo quanto quantitativo agregando incertezas sobre os resultados verificados que, as vezes, vão muito além da expectativa dos pesquisadores mais criteriosos.

A falta de uma política eficiente de correlação das informações em estudos interinstitucionais abrangentes, ou mesmo dentro de uma mesma instituição com os próprios indicadores gerenciais setoriais tem promovido o desperdício de recursos públicos na obtenção de informações irrelevantes ou mesmo relevantes mas que, devido à pouca confiabilidade das mesmas, não se prestam para indicar as tendências que pretendiam medir. Além disso, cresce o número de órgãos que recebem recursos públicos para gerar informações básicas ao seu planejamento regional, mas que por razões múltiplas, negam-se a divulgá-las ou dar acesso a essas bases de dados, constituindo crime de sonegação de informação cujas possibilidades de recurso estão acima dos usuários em geral.

Pode-se dizer que apesar da tendência da consideração da bacia hidrográfica como elemento básico de planejamento estar sendo difundida e aceita pela maior parte dos grupos ou indivíduos ligados à área, as informações sócio-culturais e principalmente econômicas necessárias para uma avaliação conjunta ainda são obtidas levando-se em conta as divisões políticas tradicionais. Assim, não se consegue, na maior parte das vezes, fragmentar adequadamente estes dados e rearranjá-los usando os contornos da bacia hidrográfica sem algum nível de aproximação, e como conseqüência, de perda.

Considerando estes elementos pouco animadores, apresenta-se como alternativa favorável o uso de indicadores baseados em escalas conceituais comparativas. O processo não exige a determinação exata da informação numérica, facilitando a checagem in loco das informações. Basta saber, por exemplo, se toda uma população é atendida por aquela variável, se apenas parte dela ou nenhuma parte da população é atendida, atribuindo-se índices para cada nível de abrangência. Este tipo de verificação tem, hoje, larga utilização nas ciências sociais, na administração de empresas com fins de implantação de programas de qualidade total (como os prêmios empresariais de qualidade), e também em algumas experiências de metodologias de priorização de investimentos em bacias hidrográficas.

Dada a pouca quantidade de informações disponíveis sobre a sócio-economia da bacia do rio Cachoeiras, a inexistência de variáveis culturais significativas para caracterizar e distinguir seus habitantes e considerando a impossibilidade de tempo e recursos para executar um levantamento adequado no local, optou-se por usar a metodologia abordada em CIDIAT (1987) que propicia uma aproximação das condições sociais baseada em 25 indicadores, como segue:

- Abastecimento urbano de água;

- Abastecimento rural de água;

- Serviço urbano de energia elétrica;

- Serviço rural de energia elétrica;

- Educação fundamental para a população urbana;

- Educação fundamental para a população rural;

- Postos de saúde para a população urbana;

- Postos de saúde para a população rural;

- Infra-estrutura urbana de recreação e esportes;

- Infra-estrutura rural de recreação e esportes;

- Serviço telefônico para a população urbana;

- Serviço telefônico para a população rural;

- Serviço telegráfico para a população urbana; 
- Serviço telegráfico para a população rural;

- Serviço de correio para a população urbana;

- Serviço de correio para a população rural;

- Nível educativo da população urbana (população analfabeta);

- Nível educativo da população rural (população analfabeta);

- Nível organizacional da população urbana;

- Nível organizacional da população rural;

- Posse de terra;

- Área das propriedades;

- Penetração campesina;

- Densidade populacional;

- Total da população atual.

Para cada variável, é determinada a situação em que se encontra a bacia hidrográfica perante uma determinada escala de valores, sendo anotados valores referenciais de importância (valor entre $0,0$ e 1,0$)$, valor relativo de cada categoria classificatória (valor entre 0,0 e 10,0) bem como a área de abrangência da medição (percentagem da área total da bacia hidrográfica abrangida pela variável).

A classificação final se dá pela aplicação da seguinte equação:

$$
\mathrm{IPA}=\sum_{\mathrm{i}=1}^{\mathrm{n}} \sum(\mathrm{VA} \times \mathrm{VR} \times \mathrm{AI})
$$

onde IPA é o índice de prioridade de ação; VA o valor referencial da variável; VR o valor relativo classificatório; AI a área de abrangência da variável e; n o número total de variáveis.

Pelo resultado obtido com cada variável (Figura 3) pode-se comparar o seu estado perante o grupo e orientar os investimentos para diminuir as discrepâncias entre elas. Os valores referenciais da importância da variável (VA) foram definidos pela importância de cada variável para a comunidade, e calculado de maneira que a soma total de seus pesos seja igual à unidade.

\section{Variáveis econômicas}

A seleção inicial das variáveis econômicas levantadas compreendeu o nível de desemprego, a renda bruta, crédito rural obtido, compra de insumos agrícolas, satisfação com a renda e tipo de moradia. A aplicabilidade dos resultados, entretanto, revelou uma série de fragilidades que descredenciaram algumas destas variáveis.

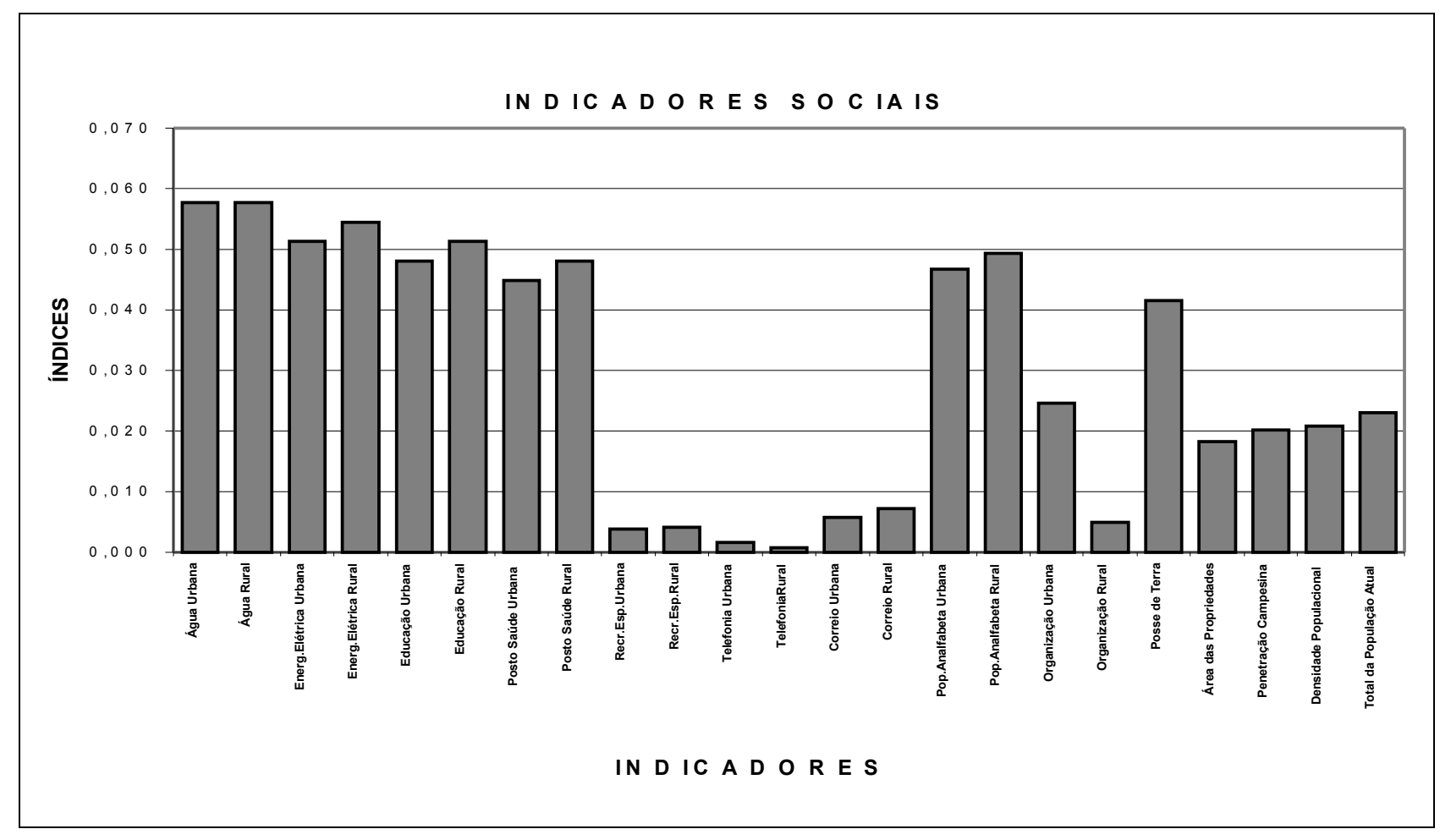

Figura 3. Variáveis sociais levantadas para a população residente na área da bacia hidrográfica do rio Cachoeiras. 
O tipo de moradia, estabelecido a priori como uma função dos materiais empregados não se revelou um bom indicador de nível econômico uma vez que, pela tradição alemã ( $25 \%$ dos moradores) ou polonesa ( $75 \%$ dos moradores) os hábitos construtivos recaem para a construção em madeira (87,5\% das edificações). Assim, observaram-se moradias de madeira melhor conservadas e de maior valor aparente que outras construções de alvenaria, ao contrário do que havia estabelecido como critério de julgamento. Deste modo, o padrão das habitações edificadas com este material não configurou uma melhor condição de moradia em relação às de madeira, descaracterizando o indicador. Como sugestão, a avaliação da condição da moradia baseada em área construída, número de cômodos ou de banheiros, bem como as condições de conservação da edificação e do lote podem constituir melhores indicadores.

Os dados da sócio-economia local revelam que a grande maioria da população economicamente ativa possui algum tipo de atividade rural. Os habitantes urbanos situados na bacia do Córrego Cachoeiras que não apresentam vínculo econômico agrícola, em geral trabalham em empregos formais fora da bacia hidrográfica, não contribuindo diretamente para a economia local. Este contingente, entretanto constitui uma minoria. Mesmo dentro dos limites da Vila Bom Jesus, os habitantes possuem alguma forma de produção (hortas) onde o excedente é comercializado através de uma cooperativa local. Assim, mesmo os habitantes considerados urbanos dentro dos limites da bacia, apresentam algum ganho econômico de cunho agropecuário.

O que se observa é que, devido ao baixo nível de comercialização dos produtos, a instabilidade do mercado dos comodities, a orientação da produção principalmente para a subsistência gerando baixos excedentes comercializáveis e à migração do habitante rural (crescimento vegetativo de $-0,19 \%$ ) ao centro urbano (taxa de crescimento de $+2,43 \%$ ), o que ocorre é uma tentativa de consorciar o salário formal com algum nível de renda do comércio de pequenos excedentes agrícolas.

A renda bruta considerada refere-se à soma da renda obtida pela comercialização de excedentes agrícolas nas propriedades rurais ao total dos salários auferidos em empregos formais. Como conseqüência da atividade agrícola predominante, os créditos agrícolas e os investimentos em equipamentos agrícolas ganham importância, mas não se aplicam à totalidade da população.
Com estas dificuldades metodológicas, optou-se por segmentar a população pela área das propriedades (fator comum aos habitantes tanto urbanos quanto rurais) e usar como indicadores econômicos apenas a Renda Bruta, e a Satisfação com a Renda (Tabela 3).

Também foi desenvolvida estratégia de valoração da satisfação com a renda, de modo a estabelecer uma escala de valores relativos para cada nível de satisfação com a renda anual auferida pela população (Tabela 4).

Considerando a freqüência observada para cada classe de tamanho de propriedade, e o Grau de Satisfação, pode-se estabelecer uma média ponderada e calcular a satisfação geral como sendo igual a 0,74 .

Da mesma forma, a Renda Bruta pode ser ponderada, avaliando-se os resultados perante uma escala comparativa que considere o rendimento anualmente obtido com o salário mínimo ( $\mathrm{R} \$ 136,00$ ou US\$ 75.50) que representaria um ganho anual de US\$ 906,00/ano, com o PIB per capita calculado para o município e equivalente a US\$2.183,34/ano e com o valor da cesta básica calculado pelo DIEESE (US\$ 5.200,00/ano) considerado como o que seria o Salário Mínimo para a manutenção de uma família média de 4 pessoas (Tabela 5).

Tabela 3. Variáveis econômicas na bacia do rio Cachoeiras.

\begin{tabular}{|c|c|c|c|}
\hline $\begin{array}{l}\text { Área } \\
\text { (ha) }\end{array}$ & $\begin{array}{l}\text { Renda bruta } \\
\text { (US\$/ano) }\end{array}$ & $\begin{array}{c}\text { Freq. } \\
(\%)\end{array}$ & $\begin{array}{c}\text { Satisfação com a } \\
\text { renda }\end{array}$ \\
\hline $0-10$ & 676,00 & 0,19 & Relativ. satisfeito \\
\hline $10-25$ & 2080,00 & 0,28 & Satisfeito \\
\hline $25-50$ & 3991,00 & 0,27 & Satisfeito \\
\hline $50-100$ & 7618,00 & 0,17 & Muito satisfeito \\
\hline$>100$ & $32.903,00$ & 0,09 & Muito satisfeito \\
\hline
\end{tabular}

Tabela 4. Valoração da satisfação dos moradores da bacia hidrográfica do rio Cachoeiras com o nível de renda.

\begin{tabular}{cc}
\hline Grau de satisfação & Valor \\
\hline Insatisfeito & 0,1 \\
Pouco satisfeito & 0,3 \\
Relativamente satisfeito & 0,5 \\
Satisfeito & 0,7 \\
Muito satisfeito & 1,0 \\
\hline
\end{tabular}


Tabela 5. Valoração da renda bruta

\begin{tabular}{cc}
\hline Classe de renda (US\$) & Índice \\
\hline $0-480,00$ & 0,1 \\
$480,00-960,00$ & 0,3 \\
$960,00-2183,34$ & 0,5 \\
$2183,34-5200,00$ & 0,7 \\
$>5200,00$ & 1,0 \\
\hline
\end{tabular}

Obs:US\$ 480,00 - equivalente a meio salário mínimo mensal; US\$ 960,00 - equivalente a um salário mínimo mensal; US\$ 2183,34 - equivalente ao PIB per capita para o município de São Mateus do Sul/PR; US\$ 5200,00 - equivalente à cesta básica do DIEESE para uma família de 4 pessoas.

O índice de renda foi, então, calculado como uma média ponderada entre a freqüência de renda e os índices representativos de cada classe de renda, e o resultado obtido foi de 0,65.

O Indicador Econômico representativo para o estudo foi calculado como a média aritmética entre os índices de Satisfação e de Renda obtidos anteriormente.

$$
\text { ÍNDICE ECONÔMICO }=\frac{0,74+0,65}{2}=0,70
$$

A escala de valores Máximo e Mínimo previstos para o Indicador Econômico varia entre 0,0 e 1,0 .

\section{Variáveis ambientais}

Foram selecionadas duas variáveis básicas para avaliar o estado geral ambiental da bacia em questão: proteção do solo e qualidade da água. Cada uma delas pode ser resumidamente apresentada como segue.

\section{Fator de proteção do solo}

O Centro Interamericano de Desarrollo Integral de Aguas y Tierras (CIDIAT, 1987) propôs uma metodologia de Diagnóstico Conservacionista de Bacias Hidrográficas baseada em fatores do clima, relevo, geologia e vegetação. A formulação original de Liano (apud CIDIAT, 1987) apresentava o fator de erosão de uma bacia hidrográfica como inversamente proporcional aos determinantes da constituição do terreno (geologia e cobertura vege- tal), e diretamente proporcional ao clima e ao relevo, conforme a seguinte equação:

$$
E(f)=\frac{C \lim a, \quad \text { Relevo }}{\text { Geolog ia , Vegetação }}
$$

Esta formulação foi modificada em CIDIAT (1987) de modo a combinar o efeito climático e a cobertura florestal original da bacia em questão. A alteração se justifica para pequenas bacias hidrográficas uma vez que nelas não se verificam, em geral, alterações espaciais significativas de clima. Além disso, a cobertura vegetal original é um fator que incorpora a influência do clima na estruturação dos extratos vegetais. Desse modo, a formulação final sugerida compõe-se da seguinte maneira:

$$
\mathrm{E}(\mathrm{f}) \quad \frac{\mathrm{CO} \cdot \mathrm{E} \cdot \mathrm{S} \cdot \mathrm{D}}{\mathrm{L} \cdot \mathrm{R} \cdot \mathrm{e} \cdot \mathrm{CA}}
$$

onde CO é a cobertura florestal original; E a erosão potencial; $\mathrm{S}$ a sedimentação medida; $\mathrm{D}$ a declividade média da bacia; L a litologia do solo; $\mathrm{R}$ a erodibilidade do solo; e a cobertura da erosão atual e; CA a cobertura florestal atual.

Uma vez que se trata apenas de um arcabouço teórico, as variáveis apresentadas na Equação (3) não apresentam unidades físicas de medição.

Os elementos necessários à aplicação desta metodologia podem ser determinados através de fatores individuais que, posteriormente, são aglutinados na conformação final do Fator de Proteção do Solo da Bacia Hidrográfica. As variáveis consideradas são detalhadas a seguir:

Cobertura florestal original - Em levantamento efetuado pela Sociedade de Preservação da Vida Selvagem e Educação Ambiental - SPVS (Bollmann, 1991) foram observados os seguintes extratos vegetais representantes da cobertura vegetal primitiva da bacia hidrográfica do Córrego Cachoeiras.

- Floresta de araucárias: Presente nas regiões mais altas, onduladas, com solo de drenagem mais alta e caracterizada pela presença do Pinheiro do Paraná (Araucária angustifolia). Entre as árvores frutíferas, registrou-se a predominância de guabirobeiras, cerejeiras e jaboticabeiras. Quanto à vegetação arbórea, verificou-se a existência da imbuia, 
carvalho brasileiro, cedro, sassafrás, canela e erva mate (de grande importância econômica na região), além de arbustos, ervas xaxins e bromélias;

- Região de várzea: Presente nas regiões aluvionares da bacia, de cota mais baixa, e devido à presença de áreas alagáveis pelas cheias do rio Iguaçú, subdivide-se em:

- Floresta ciliar (ou de Galeria): apresentando alta freqüência do branquílio e da imbuia branca, o que confere um caráter arbustivo ao substrato, além da ocorrência da aroeira, tarumã, gerivá, açoita cavalo e de uma grande variedade de epífitas e trepaderias;

- Campos de inundação: composta predominantemente de gramíneas e ciperáceas (capim navalha), cortiçeiras do brejo e branquílios.

Para estimar a cobertura florestal original (uma vez que não há registros precisos para esta microbacia em particular) considerar-se-á cada um dos extratos homogeneamente distribuído nas áreas onde ainda podem ser observados. Esta aproximação será adotada uma vez que a bacia apresenta-se relativamente bem conservada, possibilitando se observar ainda hoje, apesar das clareiras derivadas da ocupação do espaço, as características básicas da conformação florestal original e sua distribuição. Neste contexto, considerando que os terrenos acima da cota $780 \mathrm{~m}$ atendem às características apresentadas para a ocorrência da Floresta de Araucárias, admitir-se-á que este extrato florestal seja predominante nestas áreas. Da mesma forma, os campos de inundação são ainda observáveis abaixo da cota 760 m, e considerar-se-á predominante nesta parte da bacia hidrográfica. Para as outras áreas será adotada a predominância da Floresta Ciliar. Para cada tipo de cobertura vegetal, a metodologia apresenta um fator de proteção (F) adequado, definido como um grau de resistência à erosão que oferece ao terreno segundo as diversas formas de vegetação que ele sustenta (Tabela 6).

Uma vez determinado o índice de proteção do solo da bacia hidrográfica (que varia de 0,0 à 1,0 ) pode-se agregar um juízo de valor sobre o valor encontrado (Tabela 7).

Para a cobertura florestal original considerada, pode-se qualificar a bacia como sendo originalmente Muito Bem Protegida.
Tabela 6. Cálculo do fator de proteção da cobertura florestal original.

\begin{tabular}{lccc}
\hline $\begin{array}{l}\text { Cobertura } \\
\text { florestal }\end{array}$ & $\begin{array}{c}\text { Área } \\
(\%)\end{array}$ & $\begin{array}{c}\text { Fator } \\
(\mathrm{F})\end{array}$ & $\begin{array}{c}(\mathrm{F}) \times(\%) \\
\text { Mín-Máx }\end{array}$ \\
\hline $\begin{array}{l}\text { Floresta de } \\
\text { araucária; }\end{array}$ & 28,5 & 1,0 & $28,5-28,5$ \\
$\begin{array}{l}\text { Floresta } \\
\text { ciliar; }\end{array}$ & 66,9 & $0,8-0,9$ & $53,5-60,2$ \\
$\begin{array}{l}\text { Campos de } \\
\text { inundação; }\end{array}$ & 4,6 & $0,6-0,8$ & $2,8-3,2$ \\
$\begin{array}{l}\text { Soma } \\
\text { Fator de proteção médio da cobertura florestal } \\
\text { original = }((84,8+91,9) / 2) / 100)\end{array}$ & 0,88 \\
\hline
\end{tabular}

Tabela 7. Índice de proteção do solo devido à cobertura florestal.

\begin{tabular}{|c|c|c|}
\hline $\begin{array}{c}\text { Índice de proteção } \\
\text { médio }\end{array}$ & Classe & Discriminação \\
\hline $0,80-1,00$ & 5 & $\begin{array}{l}\text { Muito bem } \\
\text { protegida; }\end{array}$ \\
\hline $0,60-0,79$ & 4 & Bem \\
\hline $0,40-0,59$ & 3 & $\begin{array}{c}\text { Medianamente } \\
\text { protegida; }\end{array}$ \\
\hline $0,20-0,39$ & 2 & $\begin{array}{l}\text { Pouco } \\
\text { protegida; }\end{array}$ \\
\hline $0,00-0,19$ & 1 & $\begin{array}{c}\text { Altamente } \\
\text { desprotegida. }\end{array}$ \\
\hline
\end{tabular}

Fonte: Modificado de CIDIAT (1987).

Cobertura florestal atual - Baseado nas informações obtidas pela análise computacional em ambiente de CAD do levantamento aerofotogramétrico efetuado em 1996, levantou-se a cobertura florestal atual para a área da Bacia Hidrográfica do Rio Cachoeiras (Tabela 8). Considerando os índices de proteção do solo indicados na Tabela 7, e admitindo um fator de proteção do solo igual a 0,0 para as áreas de Estradas e Rodovias, bem como para a Ocupação Urbana e a Área de Lavra Mineral, podese calcular o Índice Geral de Cobertura Florestal Original como sendo uma média ponderada das percentagens de cada cobertura observada e dos índices de proteção individuais.

O índice médio obtido para a bacia hidrográfica do rio Cachoeira, comparado com a escala proposta para a Cobertura Florestal Atual, considera a bacia como sendo Medianamente Protegida. 
Tabela 8. Cálculo do fator de proteção da cobertura florestal atual.

\begin{tabular}{|c|c|c|c|}
\hline $\begin{array}{l}\text { Cobertura } \\
\text { florestal } \\
\end{array}$ & $\begin{array}{l}\text { Área } \\
(\%)\end{array}$ & $\begin{array}{l}\text { Fator } \\
(\mathrm{F})\end{array}$ & $\begin{array}{c}(\mathrm{F}) \times(\%) \\
\text { Mín - Máx }\end{array}$ \\
\hline $\begin{array}{l}\text { Floresta de } \\
\text { araucária; }\end{array}$ & 19,94 & 1,0 & $19,9-19,9$ \\
\hline $\begin{array}{l}\text { Floresta } \\
\text { ciliar; }\end{array}$ & 11,20 & $0,8-0,9$ & $9,0-10,1$ \\
\hline $\begin{array}{l}\text { Campos de } \\
\text { inundação; }\end{array}$ & 3,18 & $0,6-0,8$ & $1,9-2,2$ \\
\hline $\begin{array}{l}\text { Área de lavra } \\
\text { mineral; }\end{array}$ & 16,29 & 0 & 0 \\
\hline $\begin{array}{l}\text { Área de lavra } \\
\text { recuperada; }\end{array}$ & 8,76 & $0,5-0,7$ & $4,4-6,1$ \\
\hline $\begin{array}{l}\text { Área de } \\
\text { cultivo; }\end{array}$ & 16,40 & $0,2-0,4$ & $3,3-6,6$ \\
\hline $\begin{array}{l}\text { Ocupação } \\
\text { urbana; }\end{array}$ & 4,26 & 0 & 0 \\
\hline $\begin{array}{l}\text { Ocupação } \\
\text { indefinida; }\end{array}$ & 19,97 & $0,3-0,6$ & $6,0-12.0$ \\
\hline Soma & 100,00 & - & $44,4-56,9$ \\
\hline \multicolumn{4}{|c|}{$\begin{array}{l}\text { Fator de proteção médio da cobertura florestal } \\
\text { atual }=((44,4+56,9) / 2) / 100)=0,51\end{array}$} \\
\hline
\end{tabular}

Erosão potencial - Apesar da existência de várias metodologias alternativas para avaliar a erosão potencial em uma bacia hidrográfica, para manter a coerência metodológica, adotar-se-á a classificação apresentada em CIDIAT (1987) e resumida na Tabela 9.

O valor de erosão estimado para a bacia do rio Cachoeiras foi baseado no Coeficiente de Fourier, que pode ser estimado como:

$$
\mathrm{Cf}=\mathrm{p}^{2} / \mathrm{P}
$$

onde p é a precipitação máxima mensal (mm) e; P a precipitação anual (mm).

Para a bacia hidrográfica do rio Cachoeiras, o resultado obtido foi igual a 28 . O volume estimado é de aproximadamente $240 \mathrm{~m}^{3} / \mathrm{km}^{2} /$ ano (ou 6,02 t/ha/ano); qualificada como Erosão Potencial Média segundo este critério.

Sedimentação medida - O estado em que se encontra uma determinada bacia é função, entre outras variáveis, do carreamento de sólidos (sedimentos) resultantes da erosão da bacia. Portanto, esta é uma variável importante a ser analisada no diagnóstico uma vez que representa a quantidade que está sendo perdida.
Tabela 9. Determinação da erosão potencial em bacias hidrográficas.

\begin{tabular}{lcc}
\hline Classificação & Classe & $\begin{array}{c}\text { Erosão } \\
\text { (t/ha/ano) }\end{array}$ \\
\hline Erosão geológica & 5 & $<3$ \\
Erosão fraca & 4 & $3-6$ \\
Erosão média & 3 & $6-9$ \\
Erosão forte & 2 & $9-12$ \\
Erosão excessiva & 1 & $>12$ \\
\hline
\end{tabular}

Fonte: CIDIAT (1987).

Para o caso da bacia do rio Cachoeiras a medição foi aproximada pelo conteúdo médio de 12 meses de Sólidos Sedimentáveis, e uma vazão média de $140 \mathrm{l} / \mathrm{s}$, representando uma descarga de sólidos da ordem de 3,6 t/ha/ano, tida como Fraca.

Declividade da bacia - A declividade da bacia é outra variável importante a ser considerada uma vez que quanto maior for a declividade, maior será a velocidade da água, e consequentemente, maior será sua capacidade de erosão. Determinada a declividade média, pode-se qualificá-la conforme os critérios da Tabela 10.

Conforme previamente determinado, a declividade média da bacia do Córrego Cachoeiras $(0,055 \mathrm{~m} / \mathrm{m}$, ou $5,5 \%)$ a qualifica como de declividade Suave.

Cobertura da erosão atual - Dado ao seu pequeno tamanho, foi efetuada uma inspeção à bacia, e não foi verificado nenhum problema erosivo significativo, de onde se depreende que a carga de sedimentos medida deve-se à erosão geológica e à movimentação de terra observada na frente de lavra da exploração do xisto além de acessos e áreas urbanizadas. Assim, a área atingida pela erosão pode ser considerada como Muito Pequena.

Geologia - A natureza da rocha mãe e sua resistência à erosão constituem elementos chave na gênese do processo erosivo. A classificação que se propõe, baseada na estrutura litológica, fundamenta-se na degradabilidade e na instabilidade das rochas, e na susceptibilidade à erosão dos diferentes litotipos. A Tabela 11 apresenta uma classificação dos elementos geológicos sistematizados em uma escala de classes graduadas de 1 a 5 de maneira a homogeneizar os resultados com as outras variáveis. 
Tabela 10. Determinação da declividade média.

\begin{tabular}{lcc}
\hline Classificação & Classe & $\begin{array}{c}\text { Declividade } \\
(\%)\end{array}$ \\
\hline Suave & 5 & $<8$ \\
Moderada & 4 & $8-20$ \\
Moderadamente forte & 3 & $20-35$ \\
Forte & 2 & $35-45$ \\
Muito forte & 1 & $>45$ \\
\hline
\end{tabular}

Fonte: CIDIAT (1987).

Tabela 11. Propensão geológica das rochas e susceptibilidade à erosão.

\begin{tabular}{ccc}
\hline Critério & Qualificação & Classe \\
\hline $\begin{array}{c}\text { Propensão } \\
\text { geológica }\end{array}$ & $\begin{array}{c}\text { (L1) Rochas } \\
\text { duras } \\
\text { (L2) Rochas } \\
\text { friáveis } \\
\text { (L3) Rochas } \\
\text { muito friáveis } \\
\text { (L4) Rochas } \\
\text { altamente friáveis } \\
\text { (R1) Pouco } \\
\text { à erosão }\end{array}$ & 5 \\
$\begin{array}{c}\text { susceptíveis } \\
\text { (R2) Medianamente } \\
\text { susceptíveis } \\
\text { (R3) Altamente } \\
\text { susceptíveis }\end{array}$ & 3 \\
\hline
\end{tabular}

Fonte: CIDIAT (1987).

Apesar de não estar claramente apresentada em CIDIAT (1987) sua aplicação resulta nos mesmos critérios apresentados originalmente na metodologia referenciada.

Conforme Licht et al. (1997), a bacia hidrográfica do rio Cachoeiras, situada no segundo planalto possui uma composição geológica de rochas sedimentares paleozóicas da Bacia Paranaense, tais como conglomerados, arenitos, siltitos, folhelhos e calcários. Os recursos minerais incluem o carvão, calcário para corretivo de solo, urânio, folhelho pirobetuminoso para produção de óleo e materiais e construção.

Todos os Litotipos mencionados possuem uma característica Sedimentar (L1), geradora de solos qualificados como Altamente Susceptível à Erosão (R3).
Composição do fator de proteção do solo - A partir das informações observadas anteriormente, pode-se compor um único indicador de proteção do solo, sendo que os índices mínimo e máximo podem ser determinados (Tabela 12).

O índice do Fator de Proteção do Solo varia de oito (para solos altamente desprotegidos, de declividade extremamente forte, de formação litológica de rochas muito friáveis e instáveis altamente susceptíveis à erosão, observada erosão excessiva e generalizada) até 40 (para solos muito bem protegidos, de declividade suave, de formação litológica de rochas duras pouco susceptíveis à erosão, observada apenas erosão geológica em uma parte muito pequena da área considerada e com transporte de sedimentos muito baixo).

Em CIDIAT (1987) admite-se que as variáveis possuem pesos iguais de ponderação e que o índice se desenvolva de forma linear entre o valores máximo e mínimo. Para a bacia hidrográfica do rio Cachoeiras, com um Fator 32 de Proteção do Solo obtido pela soma dos índices das classes determinadas para cada uma das variáveis consideradas, obtém-se um valor normalizado de 0,75 correspondente à uma Bacia Bem Protegida conforme os critérios estabelecidos na Tabela 13.

\section{Qualidade das águas}

Como indicador da qualidade geral das águas do rio Cachoeiras, foi utilizada a formulação do Water Quality Index estabelecido pela National Sanitation Foundation dos Estados Unidos (Freitas e Requião, 1994).

Apesar das suas limitações intrínsecas, o seu uso comparativo pode auxiliar na avaliação global da qualidade geral dos recursos hídricos superficiais do rio Cachoeiras. Da mesma forma, a escala de valores apresentada (0 a 100) é adequada para efeitos de normalização uma vez que requer apenas a divisão do resultado por 100. Os pontos amostrais escolhidos foram:

- Nascentes: Apesar de não se ter coletas periódicas da qualidade das águas próximo às nascentes (NA), motivo pelo qual seus valores não estão inseridos na Figura 8, os dados existentes dão uma idéia da qualidade geral das águas sem os efeitos do uso e ocupação do solo da bacia hidrográfica, e sua média (WQI médio $=75,6)$ será considerada como o melhor valor (igual a 1,0 na escala normalizada); 
Tabela 12. Índices observados para o cálculo do fator de proteção do solo.

\begin{tabular}{lcc}
\hline Variável & Valor inferido & Classe \\
\hline Cob. flor. original & 0,88 & 5 \\
Cob. flor. atual & 0,51 & 3 \\
Decliv. média & 5,5 & 5 \\
Erosão potencial & 6,0 & 4 \\
Sedimentos & 3,6 & 4 \\
Erosão atual & 1 & 5 \\
Litologia & L1 & 5 \\
Erodibilidade & R3 & 1 \\
& Soma das classes $=32$ \\
\hline
\end{tabular}

Tabela 13. Índice de proteção total do solo.

\begin{tabular}{cl}
\hline Índice de proteção & Classificação \\
\hline 0 & Totalmente desprotegida \\
$0,01-0,19$ & Altamente desprotegida \\
$0,20-0,39$ & Pouco protegida \\
$0,40-0,59$ & Medianamente protegida \\
$0,60-0,79$ & Bem protegida \\
$0,80-0,99$ & Muito bem protegida \\
1,00 & Proteção total \\
\hline
\end{tabular}

Fonte: Modificado de CIDIAT (1987).

- Montante e jusante do Lago Sul: Uma vez que a área de mineração do xisto se desenvolveu próximo ao leito do Rio Cachoeiras, em 1993 foi efetuada a interligação deste manancial a um lago (Lago Sul) conformado pela antiga frente de lavra. Assim, o ponto de montante desta interligação (RA) espelha a qualidade das águas do córrego que perpassa uma área eminentemente rural com atividade agrícola pronunciada, e o ponto de jusante do Lago Sul (RB) reflete o efeito depurativo que o lago representa em relação ao ponto RA;

- Jusante à Vila Bom Jesus: Uma vez que a maior concentração humana da bacia hidrográfica (Vila Bom Jesus) situa-se às margens do Córrego Cachoeiras entre o Lago Sul e a rodovia estadual que dá acesso à cidade de União da Vitória, escolheu-se um ponto à jusante da referida Vila a fim de considerar a sua contribuição na alteração da qualidade das suas águas (106A).

Foz do Córrego Cachoeiras: $\mathrm{Da}$ mesma forma que nas nascentes, só se conhece a

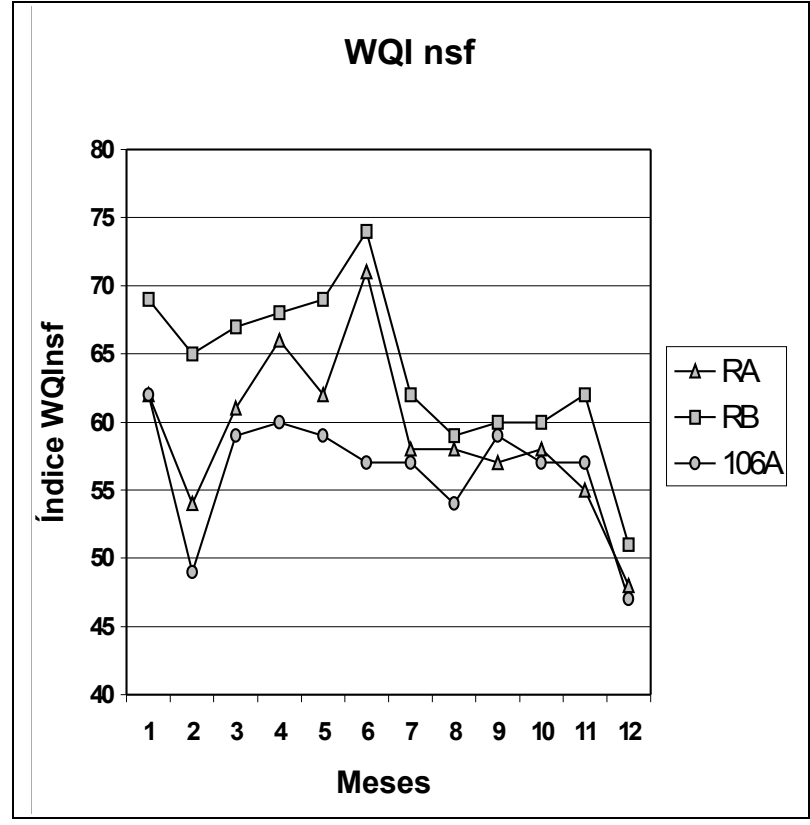

Figura 4. Índice de qualidade das águas do rio Cachoeiras entre junho/1996 e maio/1997.

qualidade das águas do rio Cachoeiras na sua foz através de alguns resultados esparsos, e por este motivo, adotar-se-á a média dos valores existentes como representativo (FZ).

Pela análise da qualidade geral das águas (Figura 4), pode-se constatar uma variação da tendência dos índices a partir do mês 06 (Dezembro de 1996), e uma das causas se deve à mineração ocorrida próximo ao rio Cachoeiras (montante do ponto RA) comprometendo a qualidade nos pontos RA, RB e 106A.

Os principais aspectos que determinaram a queda dos índices para o Ponto RA foram os parâmetros Coliformes Fecais e Sólidos Totais, que apresentaram significativo aumento principalmente na sua forma dissolvida. Observa-se também que ambos os parâmetros não são significativamente removidos no Lago Sul, motivando um comportamento similar da qualidade geral da água nos pontos RA e RB.

Esta piora progressiva, a partir do mês 06 culminou com a equiparação dos seus níveis de qualidade ao mesmo patamar do Ponto 106A que recebe ligações de esgoto provenientes da Vila Bom Jesus.

O efeito depurativo do Lago na qualidade geral das águas pode ser observado através da 
constatação de que os índices obtidos para o ponto RB sempre foram superiores.

Em razão da variabilidade dos dados, as respectivas médias de cada ponto amostral foram calculadas para representar a qualidade das águas, a saber:

$$
\begin{array}{ll}
\text { NA: } & \text { WQI médio }=76 \\
\text { RA: } & \text { WQI médio }=59 \\
\text { RB: } & \text { WQI médio }=64 \\
\text { 106A: } & \text { WQI médio }=56 \\
\text { FZ: } & \text { WQI médio }=50
\end{array}
$$

A qualidade geral das águas do rio Cachoeiras pode então ser determinada pela variação dos seus índices de qualidade, considerando as perdas a partir das nascentes (Tabela 14).

Verificou-se a variação da qualidade das águas, comparando os resultados obtidos para o rio Cachoeiras com uma curva teórica na qual se admite que ao longo de sua extensão $(7,2 \mathrm{~km})$ ocorra a perda total da qualidade (WQI $=0)$, ou seja, com perda total de 76 unidades de qualidade (Figura 5). Neste caso hipotético, considera-se que a perda máxima corresponde ao índice 1,0.

Para o caso do outro extremo teórico, onde a qualidade das águas das nascentes se mantém ao longo de todo o manancial, ou seja, não haja perda de qualidade, considera-se um índice de perdas de qualidade igual a 0,0 .

A área determinada pela aplicação dos dados médios de qualidade das águas (Tabela 14) à representação espacial de sua variação (Figura 5) corresponde à perda real de qualidade observada na bacia do rio Cachoeiras, motivada pelos padrões de uso e ocupação de seu solo.

A área definida pela linha pontilhada e o eixo $x$ pode ser calculada como $(76 \times 7,2) / 2=273,6$ e corresponderá ao Índice 1,0 de perda de qualidade (perda total). A perda observada para o rio Cachoeiras corresponde a 82,7 (área sombreada) e o índice da perda de qualidade das águas será:

$$
\Delta \mathrm{PWQI}=\frac{82,7}{273,6}=0,30
$$

significando que, em média, a perda da qualidade das águas devido aos padrões de uso e ocupação do solo representa cerca de 30\% em relação à qualidade das nascentes.

Para manter a orientação geral adotada na qual o pior valor representa um índice de 0,0 e o
Tabela 14. Variação da qualidade das águas do rio Cachoeiras.

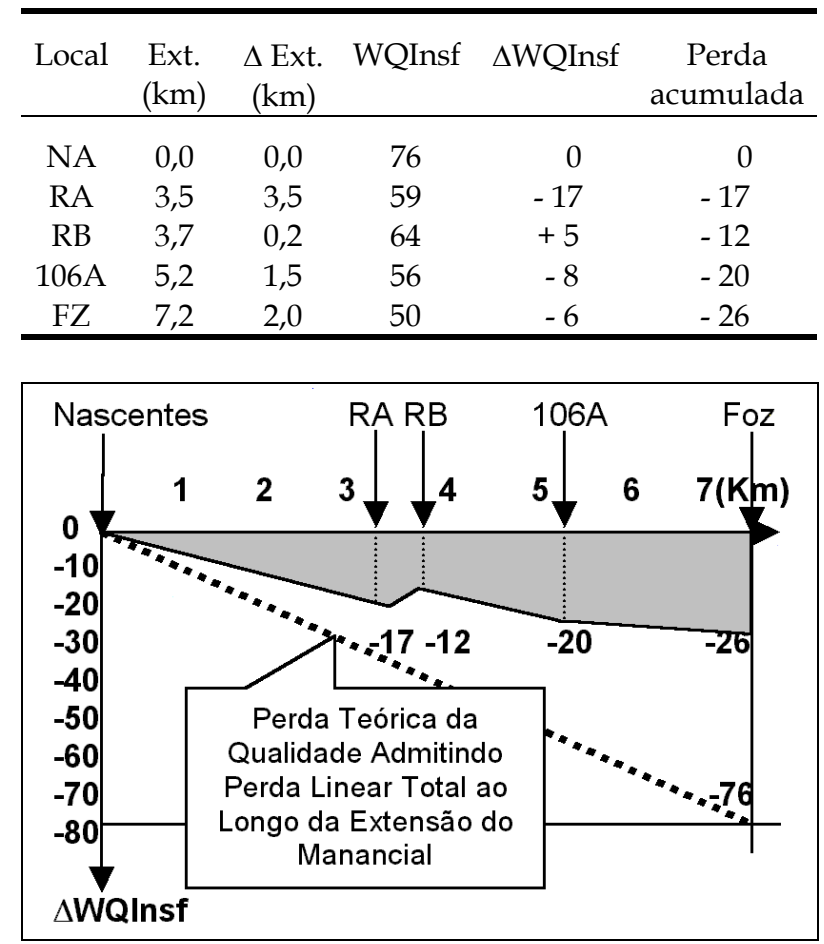

Figura 5. Perda da qualidade das águas do rio Cachoeiras devido ao uso e ocupação do solo.

melhor valor um índice unitário, o Indicador Médio de Qualidade das Águas adotado será calculado como sendo:

$$
\mathrm{IMQA}=(1-\mathrm{PWQI})
$$

ou seja:

$$
\operatorname{IMQA}=(1-0,30)=0,70
$$

\section{ANÁLISE MULTICRITERIAL}

Para dar uma idéia da abrangência global das variáveis consideradas na avaliação econômica e ecológica da bacia em estudo, é necessário resumir as informações até agora obtidas (Tabela 15). Para esta análise, será adotada uma estratégia de correlação entre o nível de qualidade sócio-econômica da população residente e a qualidade ambiental geral da bacia. Será admitido nesta análise que as variáveis possuem pesos wij iguais uma vez que não foi possível estabelecer uma relação de predominância da importância da variável social ou econômica para a população, nem da qualidade da água ou do solo para o caso da qualidade ambiental. 
Tabela 15. Resumo dos índices e indicadores calculados.

\begin{tabular}{|c|c|c|c|}
\hline Sócio-economia & Variáveis & Meio ambiente & Variáveis \\
\hline $\begin{array}{l}\text { Indicador } \\
\text { social } \\
\mathrm{Y} 11=0,69 \\
(0,0 \text { a } 1,0) \\
\mathrm{W} 11=0,5\end{array}$ & $\begin{array}{c}\text { Abastecimento de água } \\
\text { Energia elétrica } \\
\text { Educação fundamental } \\
\text { Postos de saúde } \\
\text { Recreação e esportes } \\
\text { Telefonia } \\
\text { Correios } \\
\text { Analfabetismo }\end{array}$ & $\begin{array}{l}\text { Proteção do } \\
\text { solo } \\
\text { X21 }=0,75 \\
(0,0 \text { a } 1,0) \\
\text { W21 }=0,5\end{array}$ & $\begin{array}{c}\text { Cobertura florestal original } \\
\text { Cobertura florestal atual } \\
\text { Declividade média } \\
\text { Litologia do solo } \\
\text { Sedimentação medida } \\
\text { Erosão atual } \\
\text { Erodibilidade } \\
\text { Erosão potencial } \\
\end{array}$ \\
\hline$W 11=0,5$ & $\begin{array}{l}\text { Nível organizacional } \\
\text { Posse da terra } \\
\text { Área das propriedades } \\
\text { Penetração campesina } \\
\text { Densidade populacional } \\
\text { População absoluta } \\
\end{array}$ & $\begin{array}{l}\text { Qualidade } \\
\text { geral das } \\
\text { águas } \\
X 22=0,70 \\
(0,0 \text { a } 1,0)\end{array}$ & $\begin{array}{c}\text { pH } \\
\text { Turbidez } \\
\text { Oxigênio dissolvido } \\
\text { D.B.O. } 5 \text { dias } \\
\text { Nitrogênio (NTK) } \\
\text { Fósforo }\end{array}$ \\
\hline 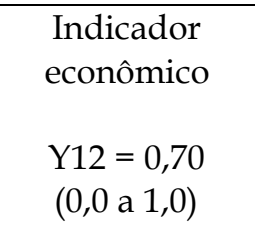 & $\begin{array}{c}\text { Renda bruta } \\
\text { Satisfação com a renda }\end{array}$ & $W 22=0,5$ & $\begin{array}{l}\text { Sólidos totais } \\
\text { Temperatura da água } \\
\text { Coliformes fecais }\end{array}$ \\
\hline$W 12=0,5$ & & & \\
\hline
\end{tabular}

Com isso, o cálculo das coordenadas cartesianas do Ponto de Equilíbrio Atual pode ser feito pelas Equações (6) e (7) a seguir:

$$
\begin{aligned}
& X=\Sigma(X i j \cdot w i j) \\
& Y=\Sigma(Y i j \cdot w i j)
\end{aligned}
$$

Os valores de $\mathrm{X}$ e $\mathrm{Y}$ podem ser obtidos como:

$$
X=(0,69) 0,5+(0,70) 0,5=0,70
$$

A componente $X$ pode variar entre o mínimo de 0,69 (quando $w 11=1,0$ e $w 12=0,0$ ) e 0,70 (quando $\mathrm{w} 11=0,0$ e w12 = 1,0).

Para a componente Y obtém-se, de modo semelhante, os seguintes valores:

$$
Y=(0,70) 0,5+(0,75) 0,5=0,72
$$

com o valor mínimo de 0,70 e valor máximo de 0,75 .

A proximidade entre os valores mínimo e máximo dos indicadores reforça a tese de adoção de pesos iguais. $\mathrm{O}$ ponto de equilíbrio sócio- econômico e ambiental atual para o caso da bacia hidrográfica do rio Cachoeiras resultou em um valor muito próximo à área definida como de equilíbrio Positivo (Figura 6). Além disso, os valores calculados para as coordenadas $\mathrm{X}$ e $\mathrm{Y}$ igualmente não diferem muito, revelando um bom equilíbrio entre a qualidade sócio-econômica da população e a qualidade ambiental (entendidos apenas como o resultado da consideração das variáveis apresentadas).

Uma vez que a metodologia permite que se obtenham vários cenários de atuação, onde é possível prescrever ações concretas na melhora das condições sócio-econômicas ou ambientais mais deficientes, far-se-á, a título de exemplo, um estudo complementar de atendimento a uma condição considerada "ótima dominante". O ponto de equilibrio almejado entre as condições sócio-econômicas e ambientais possui as coordenadas 0,72; 0,72 (Figura 6). Este ponto foi escolhido por três razões básicas:

- mantém o estado de preservação ambiental inalterado;

- possibilita um ganho real em termos sócioeconômicos à população, produzindo um 


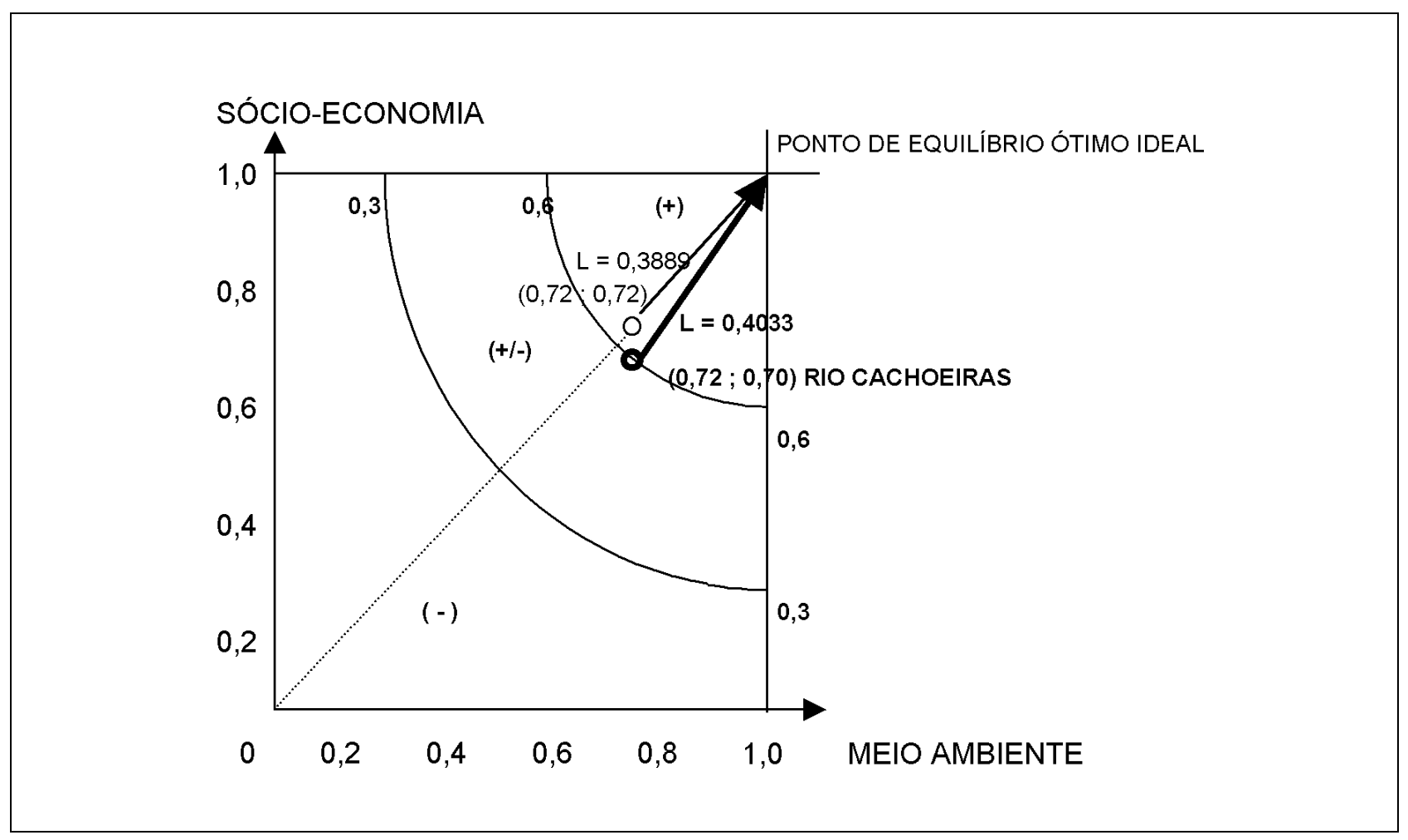

Figura 6. Representação final do ponto de equilíbrio do rio Cachoeiras no modelo UNESCO 87.

melhor equilíbrio com a qualidade ambiental inferida;

- situa o Ponto de Equilíbrio para dentro da área de Equilíbrio Positivo, diminuindo sua distância ao Ponto de Equilíbrio Ideal.

Nesta situação, observa-se que, em termos de planejamento, a preocupação ambiental tem o mesmo peso da motivação sócio-econômica, e cabe à análise decidir, através de um algoritmo de otimização multicriterial, quais os investimentos ótimos a serem feitos para se atingir esse objetivo.

Para a bacia do rio Cachoeiras, uma vez que os custos de investimentos não puderam ser valorados para cada variável, adotar-se-ão como base de referência os dados atualizados levantados em Mascaró (1987) bem como algumas estimativas de custo. Considerou-se, nesta aplicação, uma população urbana de 2600 habitantes, e 280 habitantes no meio rural. Portanto, a população objeto de será definida como aquela necessária, no meio rural ou urbano, ao atingimento do nível de equilíbrio preconizado com investimento mínimo. O objetivo desta aplicação é determinar qual a prioridade de investimentos para que o índice social passe de 0,69 para 0,73 (uma vez que deste modo, o índice global sócio-econômico passaria de 0,70 para 0,72 ). Define- se, portanto, a necessidade de aumentar o índice referente ao Desenvolvimento Econômico em 0,04 unidades uma vez que se aceita adequado o nível de conservação ambiental atual.

Como se pretende elevar o nível sócio econômico, sem prejuízo ambiental, em primeiro lugar, determinar-se-á quais as variáveis prioritárias. Estas consistem no grupo de variáveis que apresentaram pior desempenho, e sua melhoria representará um melhor equilíbrio interno no universo sócioeconômico considerado.

Para a intervenção nas variáveis econômicas selecionadas (Renda Bruta e Satisfação com a Renda), duas soluções poderiam ser levantadas:

- Investimentos para alavancar uma melhoria salarial da população de baixa renda através do incentivo à produção e à geração de empregos (cuja eficácia estaria associada à um elevado grau de incerteza pela atual conjuntura macroeconômica, pelas limitações orçamentárias normais do governo municipal e pela incerteza de que a melhoria salarial afetaria na mesma medida o grau de satisfação da população de baixa renda); 
- Empregar um contingente suficiente da população de baixa renda em serviços remunerados de modo que houvesse a melhoria da distribuição de renda (o que não se adequaria às políticas de contratação por concurso público que privilegiam os de melhor formação - e geralmente de melhor situação sócio-econômica, contraria a tendência vigente de enxugamento do funcionalismo público, além de se estar sujeito à uma reversão desta situação na ocasião de mudança do Prefeito).

Por estes motivos, optou-se por trabalhar apenas com as variáveis sociais, que teoricamente se constituem como dever do Estado. Para isso, os indicadores sociais foram reordenados sob uma ótica puramente econômica, na qual serão privilegiadas as variáveis com maior peso global (VA.VR.AI) e que têm, assim, maior poder de modificar o resultado.

Deve-se observar que esta regra leva em conta apenas o ponto de vista do gestor urbano, e nem sempre as prioridades obtidas nesta situação refletem as aspirações do público alvo. Este desvio de orientação, entretanto, não se constitui motivo sério de ponderação, uma vez que o equilíbrio sócio-econômico e ambiental se encontra naturalmente em boas condições, e se pretende apenas um "polimento" das políticas públicas no sentido de otimizar este equilíbrio.

Percebe-se a importância dada ao acesso ao abastecimento de água potável, energia elétrica, educação e saúde, o que corresponde aos anseios normais de qualquer extrato populacional. Em sua maioria, entretanto, esses serviços já se encontram razoavelmente bem implantados. Necessário se faz apresentar uma idéia dos investimentos em relação ao serviços deficitários (Tabela 16).

Considerando que o $\Delta \mathrm{Y}$ necessário é de $(0,73-0,69=0,04)$, as opções de investimento se resumem às combinações apresentadas na Tabela 17.

Pela análise das alternativas de investimento (Tabela 16), pode-se verificar que as opções 1,2 , $3,1+2$ e 2+3 não atingem o nível de variação de $\Delta Y$ necessário e igual a 0,04. Todas as demais opções superam este valor.

Dentre estas opcões, a que representou menor custo total é a opção $1+5.2$, ou seja, a construção de uma escola consorciada à um centro esportivo e de lazer para atender às populações rural e urbana locais. $\mathrm{O}$ investimento total estimado é de US\$ 48.000,00.

Percebe-se que o gráfico da Figura 7 apresenta dois grupos de dados distintos. O grupo mais à esquerda (apresentando menor volume de investimento) representa as alternativas nas quais não se considera a Opção 2 (Regularização da Posse de Terra).

O grupo à direita (apresentando maior investimento) representa as alternativas que contemplam a Opção 2 (que apresenta o maior custo unitário). Descartando-se esta alternativa, e considerando apenas as possíveis combinações entre as Opções 1, 3, 5.1 e 5.2, pode-se estimar uma curva de investimentos sociais baseado na variação do índice de qualidade social geral para a bacia (Figura 8).

Tabela 16. investimentos para atingir o equilíbrio econômico e ambiental na bacia hidrográfica do rio Cachoeiras.

\begin{tabular}{|c|c|c|c|c|}
\hline Opções & Indicador $^{1}$ & Ação & Custo (US\$) ${ }^{2}$ & $\Delta \mathrm{Y}^{3}$ \\
\hline 1 & Nível educacional; & $\begin{array}{l}\text { Construção de núcleo educacional para } 288 \\
\text { analfabetos urbanos/rurais; }\end{array}$ & $30.000,00$ & 0,017 \\
\hline 2 & Regularização da posse de terra; & Título de propriedade a 144 famílias; & $384.000,00$ & 0,005 \\
\hline 3 & Penetração campesina; & $\begin{array}{l}\text { Desapropriar e preservar } 81 \text { ha nas nascentes } \\
\text { do córrego Cachoeiras; }\end{array}$ & $67.000,00$ & 0,025 \\
\hline 4 & Serviço de correio; & Implementação de subagência dos Correios; & 4 & 0,016 \\
\hline 5 & Recreação e esportes; & 5.1. Centro poli-esportivo novo; & $62.000,00$ & 0,072 \\
\hline & & 5.2. Consorciado à escola do item 1 ; & $18.000,00$ & 0,035 \\
\hline 6 & Serviço telefônico; & $\begin{array}{l}\text { Atender } 2.412 \text { habitantes ( } 600 \text { economias com } \\
\text { telefone público e domiciliar; }\end{array}$ & 4 & 0,026 \\
\hline
\end{tabular}

\footnotetext{
${ }^{1}$ Indicadores deficitários, por ordem de prioridade; ${ }^{2}$ Mascaró (1987) e dados aproximados obtidos junto à prefeitura municipal de São Mateus do Sul; ${ }^{3}$ Variação total (urbana e rural) entre o peso do indicador atual e o peso que passaria a ter na implementação total do indicador; ${ }^{4}$ Ações consideradas fora do âmbito da prefeitura municipal.
} 
Tabela 17. Opões de investimento.

\begin{tabular}{crc}
\hline Opções $^{1}$ & Custo (US\$) & $\Delta Y$ \\
\hline 1 & $30.000,00$ & 0,017 \\
2 & $384.000,00$ & 0,005 \\
3 & $67.000,00$ & 0,025 \\
5.1 & $62.000,00$ & 0,072 \\
$1+2$ & $414.000,00$ & 0,022 \\
$1+3$ & $97.000,00$ & 0,042 \\
$1+5.1$ & $92.000,00$ & 0,089 \\
$1+5.2$ & $48.000,00$ & 0,052 \\
$2+3$ & $451.000,00$ & 0,030 \\
$2+5.1$ & $446.000,00$ & 0,079 \\
$3+5.1$ & $129.000,00$ & 0,097 \\
$1+2+3$ & $481.000,00$ & 0,047 \\
$1+2+5.1$ & $476.000,00$ & 0,094 \\
$1+2+5.2$ & $432.000,00$ & 0,057 \\
$1+3+5.1$ & $159.000,00$ & 0,124 \\
$1+3+5.2$ & $115.000,00$ & 0,077 \\
$1+2+3+5.1$ & $543.000,00$ & 0,119 \\
$1+2+3+5.2$ & $499.000,00$ & 0,082 \\
\hline
\end{tabular}

1 Opções de investimentos da Tabela 16.

Pela sua análise pode-se ter uma idéia dos montantes a serem investidos para o aumento ao nível que se quer atingir de qualidade de vida social.

\section{CONCLUSÕES}

A escolha das variáveis e das estruturas de agregação dos indicadores deve corresponder àquelas mais representativas e sensíveis ao caso que se quer estudar. Para levantar com clareza as deficiências sócio-econômicas e ambientais com as quais se quer trabalhar, o gestor poderá adotar uma de três alternativas possíveis: a) realizar os investimentos através de uma priorização obtida da consulta direta à população alvo. Neste caso, os indicadores baseados nos dados obtidos através de pesquisa de opinião são privilegiados uma vez que, com o atendimento direto às reivindicações da população, este tipo de variáveis apresentam um retorno rápido em relação aos investimentos feitos; b) adotar uma postura puramente técnica, realizando os investimentos nas ações que apresentam um retorno ótimo sob o ponto de vista econômico; c) elaborar uma postura mista, onde se procura adequar as necessidades e aspirações da população às ações consideradas prioritárias do ponto de vista

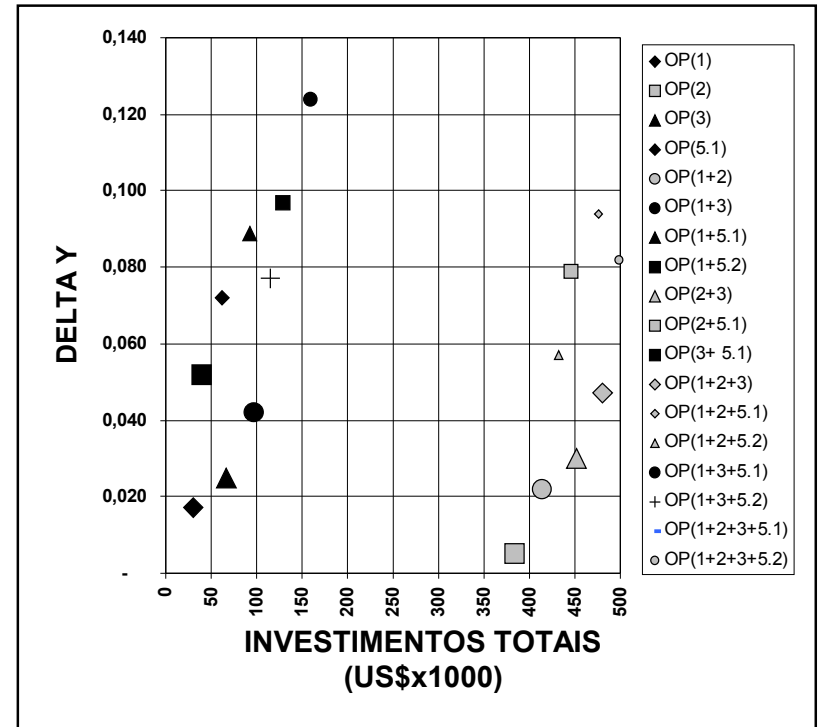

Figura 7. Alternativas de investimento.

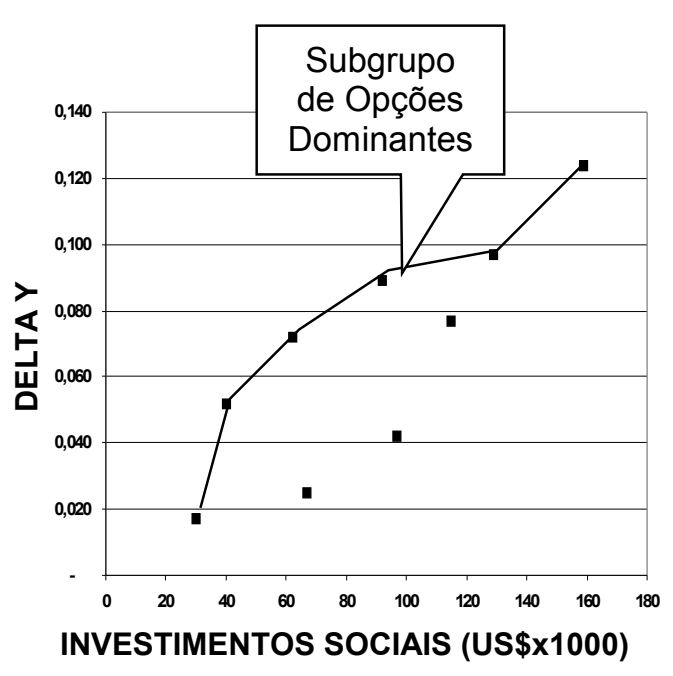

Figura 8. Impacto dos investimentos sociais na variação do índice de qualidade social.

técnico. Observa-se que nem sempre estas aspirações coincidem com as prioridades elencadas através de preceitos técnico-econômicos. De fato esta alternativa não é tão confortável uma vez que necessita da negociação das prioridades com a sociedade, mas, a médio e longo prazo, esta prática pode trazer bons resultados.

Os pesos adotados não apenas para as variáveis individuais, mas para os indicadores de ordem superior, possuem uma grande influência nos valores das coordenadas finais. Esta influência, entretanto, será tanto menor quanto menores forem as diferenças entre os índices normalizados dos vários indicadores selecionados. 
Para se verificar o resultado efetivo da aplicação dos recursos, é preciso o levantamento repetitivo das informações necessárias à aplicação do modelo, de modo a se analisar periodicamente a evolução do ponto de equilíbrio no campo das soluções possíveis, podendo-se mesmo obter uma relação entre o volume de investimentos efetuados e a variação da distância entre o ponto de equilíbrio atual e o ideal (distância L no gráfico final do Modelo).

É possível a adição ou subtração de variáveis e indicadores do rol daqueles inicialmente considerados desde que se possa recalcular os pontos de equilíbrio anteriores, de modo que a metodologia apresenta um certo grau de flexibilidade importante no sentido de melhoria contínua do processo de medição.

A metodologia permitiu a consideração de variáveis de difícil mensuração (como por exemplo a da satisfação da população) pelo fato de que cada variável é julgada perante uma escala de valores próprios, e seus resultados são transformados em uma escala comum adimensional, não necessitando estabelecer-se um elemento de transformação de variáveis. Esta possibilidade vem de encontro às necessidades da realidade brasileira que é caracterizada por decisões baseadas muitas vezes em critérios não facilmente mensuráveis (decisões políticas, preferências pessoais e intuitivas etc.), e pela falta de bancos de informações consistentes elaborados por bacias hidrográficas.

Além da possibilidade de análise temporal, pode-se executar comparações entre bacias hidrográficas distintas para a priorização de ações, desde que cada uma seja medida perante critérios próprios que melhor descrevam sua situação (não necessariamente as variáveis são as mesmas para todas as bacias).

A consideração de custos de investimentos para as variáveis arroladas possibilita a otimização do uso dos recurso públicos e privados e pode ser feita através do uso de algoritmos de otimização multicriterial. A observação que se faz é no sentido de adequar a forma de variação de cada indicador (comportamento linear, não linear ou por patamares de classe) à métodos de programação linear, não linear ou por inteiros. Observa-se que a determinação de custos unitários por habitante ou por unidade de área facilitam extraordinariamente a otimização. Além disso, o gestor pode, com base nas respostas apresentadas pela aplicação do modelo, elaborar cenários futuros consistentes podendo negociar com a população envolvida e com as instituições responsáveis, as prioridades de investimentos e o nível de atendimento que se pretende chegar.

Como visto anteriormente, além das dificuldades metodológicas de obtenção das informações (falta de consistência e confiabilidade dos dados, existência de uma grande massa de dados inúteis ao planejamento, etc.), ao gestor se apresenta outra dificuldade baseada no acesso a estas informações, que devido à amplitude da consideração sócio-econômica, cultural e ambiental, está dispersa em vários bancos de informações fragmentados em instituições muitas vezes concorrentes, e cujo acesso é difícil. Deste modo, o comprometimento destas instituições em participar da aplicação do modelo em todas as suas fases é um elemento fundamental para o sucesso dos trabalhos.

Verifica-se que o modelo aplicado representa um avanço considerável em relação à prática de gestão tanto pela amplitude da análise quanto pela flexibilidade de sua aplicação. Para o caso da bacia hidrográfica do Córrego Cachoeiras, as variáveis relativas ao meio ambiente são em sua maioria descritores que medem o estresse causado pelo impacto antrópico, apontando algumas alterações previamente determinadas no espaço ecológico.

A presença de poluentes produz alterações complexas e particulares nas condições ecológicas locais, intervindo de maneira significativa nas comunidades biológicas, cuja alteração pode não ser linear e, neste caso, a adoção de indicadores de condição ecológica (e não de estressores) pode ser mais esclarecedora.

A dificuldade que se tem para executar esta outra abordagem reside na tarefa de prédeterminar o valor destes indicadores para uma situação ausente da ação humana naquele ambiente específico (condição ótima ambiental). Os indicadores atuais dão, de fato, pouco valor ao ponto de vista do ambiente na sua íntegra, e as qualidades indicadas em geral visam a atender demandas do homem (e seus padrões de qualidade ambiental) sem se preocupar com os padrões de equilíbrio natural e as demandas das comunidades biológicas também envolvidas.

A adoção de novos indicadores com estas características, e sua aplicação à metodologia ora em discussão, pode assim permitir uma avaliação do estado dos recursos ecológicos na bacia hidrográfica, permitindo verificar se os recursos respon- 
dem como previsto em relação à aplicação de programas de regularização e controle ambiental embutidos nos planos de gestão.

\section{AGRADECIMENTOS}

Os autores agradecem ao Instituto de Saneamento Ambiental - ISAM/PUCPR, Projeto Mananciais/PADCT III (FINEP/SPC:8898076100) pelo apoio e fornecimento dos dados, e em especial à estagiária Cláudia Fenner Parra; ao $\mathrm{CNPq}$ pelo auxílio na forma de Bolsas de Pesquisa; e à FINEP/PRONEX (FINEP/ FAUFRGS:7697101900) no qual se insere o trabalho.

\section{REFERÊNCIAS}

AJZENBERG, M. G. et al. (1986). Utilização de indicadores de caráter social na definição de prioridades de obras de saneamento, In: Revista $D A E$, vol. 46, n¹47, p. 392-401. São Paulo.

BOLLMANN, H. A. (1991). Recuperação da área degradada pela mineração do xisto em São Mateus do Sul - PR. Solicitação de Financiamento enviada ao Programa PADCT II do Ministério da Ciência e Tecnologia. Instituto de Saneamento Ambiental da PUCPR, Curitiba/PR, 386 p.

CIDIAT (1987). Manejo conservacionista de bacias hidrográficas. Metodologia para o levantamento da importância dos recursos naturais e seus respectivos fatores de degradação. Centro Interamericano de Desarrollo Integral de Aguas y Tierras e Superintendência de Desenvolvimento da Região Sul. Vol. 1 e vol. 2. Itajai/SC.

DUVAL, G. (1993). Investigación interdisciplináira y enfoque sistémico. Rev. Avance y Perspectiva, vol. 12, mar-abr, p. 67-76.

FREITAS, C. O. A. e REQUIÃO, L. C. M. (1994). Índice de qualidade das águas - IQA. Manual do IQA versão 4.0. ISAM/PUC-PR, Curitiba, Paraná; p. 18.

FUNTOWICZ, S. O. e RAVETZ, J. R. (1994). Emergent complex systems. Rev. Futures, vol. 26, $\mathrm{n}^{\circ} 6$, p. 568-582.

IISD (1998). Measurements and indicators program. International Institute for Sustainable Development. http:/ /iisd1.iisd.ca/about/m\&i.htm

LICHT, O. A. B; PIEKARZ, G. F; SILVA, J. C. C. e LOPES Junior, I. (1997). Levantamento geoquímico multielementar de baixa densidade no Estado do Paraná: Hidrogeoquímica - resultados preliminares. Rev. A Terra em Movimento, n³, Julho/97, p. 34-46.

MASCARÓ, J. L. (1987). Desenho urbano e custos de urbanização. Ministério da Habitação, Urbanismo e Meio Ambiente. Brasília/DF. 190 p.
MUTZ, D. (1991). Ökologische und sozio-ökonomische kriterien für standeortentscheidungen bei abfalldeponien in ländern der dritten welt. Universität Karlsruhe. Doktor - Inginierus Dissertation. Hauptreferent: Prof. Dr. Rer. nat. Ludwig Hartmann. Karlsruhe Deuschland. $164 \mathrm{p}$

UNESCO (1987). Methodological guidelines for the integrated environmental evaluation of water resources development. Projeto FP/5201-85-01/UNEP - Dr. Ludwig Hartmann (Coordenador). United Nations Educational, Scientific and Cultural Organization, Paris; p. 152.

VILELLA, S. M. e MATTOS, A. (1975). Hidrologia aplicada. McGrall Hill do Brasil, São Paulo - SP. 245 p.

\section{Integrated Environmental Management of River Basins: Cachoeiras River Basin - São Mateus do Sul - PR}

\section{ABSTRACT}

The integrated environmental management of river basins can be based on a multicriteria approach that establishes an ecology/economy equilibrium point and calculates the distance to an ideal point considered as a reference. This approach was applied to Cachoeiras River Basin, and the results show the optimal investments to reach a hypothetical equilibrium where the socio-economic and environmental aspects are equally important. Furthermore, it is concluded that ecological indicators (condition and stressors) needs to be considered if we really want to determine the environmental status and changes either due to stressors or management decisions.

Key-words: menagement; integrated; basin. 